\title{
An investigation of slag floatation and entrapment in a continuous-casting tundish using fluid-flow simulations, sampling and physical metallurgy
}

\author{
Henrik Solhed ${ }^{1,2}$ and Lage Jonsson ${ }^{1,3}$ \\ ${ }^{1}$ MEFOS, Luleå; ${ }^{2}$ Department of Physics, Lulea University of Technology; ${ }^{3}$ Department of Materials Science and Engineering, KTH, Stockholm, Sweden
}

\begin{abstract}
Some aspects of inclusion behaviour in the tundish have been investigated both theoretically and experimentally. Good agreement was obtained between measured and predicted temperature and flow fields for 1 - to 6-strand continuouscasting tundishes. In this study the flow field was redesigned with weirs, resulting in the addition of a vertical component to Stoke's equation. The results indicate an increase in the velocity that cause a rise of inclusions (smaller inclusions $(<20 \mu \mathrm{m}))$. Consideration of slag, flux and refractory in the model has also made it possible to simulate the mixing of steel and slag. Special sampling techniques were used to gather information. Samples were analysed using ultrasonic testing,
\end{abstract}

LOM, SEM and Atomic Force Microscopy (AFM). The analysis results were used to verify the predictions regarding steel/slag mixing and understanding of physical conditions at the interfaces. As a result, the casting praxis was improved (cleaner steel) and the products were of higher quality.

Key words: clean steel, fluid flow, microscope studies, mixing, models, sampling, slag, steel, theory, tundish.

(C) Blackwell Munksgaard, 2003

Accepted for publication 24 May 2002
Extensive efforts have been made in academia and industry over the past decades to exploit and enhance continuous-casting-tundish systems with respect to their metallurgical performance. As a consequence, numerous physical and mathematical modelling studies embodying both industrial and water-model tundishes have been carried out and reported in the literature. Recently, Mazumdar \& Guthrie [1] reviewed these modelling efforts of continuous-casting systems. They pointed out that a modern-day steel-making tundish should be designed to provide maximum opportunity for carrying out various metallurgical operations such as inclusion separation, flotation, alloy trimming, inclusion modification, superheat control, as well as thermal and particulate homogenisation. Furthermore, they concluded that mathematical studies indicate that flow conditions conducive to the removal of non-metallic inclusions from tundishes can be created by inserting appropriate flow-modification devices. The optimal design and location of flow modifiers, with respect to clean steel, clearly depend on tundish geometry [2], the operating conditions and very much on the steel inclusions' size range.
In the models reported on, however, the refractory has rarely been included and, to the knowledge of the authors, neither the flux nor liquid slag have so far been included in any modelling efforts. It is obvious though that both the refractory and the slag layer preferably should be the integrated parts of the model for appropriate understanding of many metallurgical issues such as thermal and inclusion behaviour because the slag and the refractory are both potential sources, sinks and modifiers for inclusions. Furthermore, a useful approach to modelling fluid flow in the slag phase enables studies of heat and fluid-flow conditions coupled with thermodynamics in the very important steel/slag region (from a metallurgical point of view) in a continuous-casting tundish. The alternative of coupling fluid flow and thermodynamics would be to use the 2-film theory [3-7]. However, use of the surface-renewal theory to couple thermodynamics and fluid flow might not be adequate when slag and metal are mixed, and it certainly would not allow for the study of the mixing itself. Therefore, as a first step towards a process model of a continuouscasting tundish, a model of a tundish built on the basis of fundamental equations, which takes slag, flux and 
refractory into account, has been developed and is presented in this paper.

Specifically, the model reflects the penetration of the steel and slag phases into each other and other conditions at the slag/metal interface. Many authors have studied the dispersion of the slag phase into the steel using physical modelling [8-15]. Among them Kim et al. [13] determined a critical stirring rate for the break up of the interface in a ladle. From their results it is evident that the interface is fully disintegrated and a mixing zone establishes above a certain stirring rate, but it can also be deduced that a certain degree of mixing exists even for low flow rates. Furthermore, Spalding and Villasenor [16] have shown, using a long duct of rectangular cross section and 2 fluids of different densities, that the instability that arises because of the presence of shear between the fluid layers will cause a mixing of the layers. They also showed that this instability could be predicted by a fluid-flow calculation, if the position of the interface was calculated. The authors of this paper used these ideas to incorporate the liquid slag phase into their model of a continuous-casting tundish. The predictions of heat and fluid flow were validated by comparison with both velocity and temperature measurement data from production-scale tundishes. Furthermore, the fluid-flow model including the slag phase has been validated by investigation of steel/slag samples taken with a special sampling device [17]. Studying these samples also revealed some information on steel-inclusion interaction.

The modelling is described in the section on mathematical modelling. Thereafter, in the next section, the solution procedure including initial and boundary conditions is discussed. The flow and temperature field results are presented in the next section. In a further section, the slag entrapment results are described as well as the sampling technique, the methods used to investigate the samples and the results of the investigation. Finally, the next sections include a discussion of the presented results, some conclusions and some suggestions on future work.

\section{Mathematical modelling}

The continuous-casting tundish has increasingly evolved into a very useful reactor for steel refining. However, the operating conditions, high temperature and visual opacity of liquid steel make it hard to make direct experimental investigations. Mathematical modelling is a reasonable alternative to investigate fluid-flow and heat-transfer phenomena in continuouscasting tundishes. Today, a large number of modelling efforts covering various aspects such as fluid flow, residence time, inclusion and thermal energy transport, etc. have been reported in the literature. These works have led to considerable improvements in our understanding of the various transport processes associated with tundish operations. However, most of the modelling efforts have not included the refractory, slag or flux. Considering refractory, slag and flux in the model should on the one hand render a better prediction of heat and fluid flow, but most importantly make it possible to couple thermodynamic calculations on inclusion chemistry, solidification processes etc. with macro-kinetics derived from first principles. This has been the driving force for the development of the model of a continuous-casting tundish, which besides the steel phase also takes the refractory, slag and flux into account. The basic ideas behind the development of the model are given in the next subsection and the conservation equations in the subsection thereafter. The property variations of the different phases are given in the succeeding subsection, together with the other auxiliary equations and in the last subsection the boundary conditions are stated.

\section{Basic ideas behind the modelling}

Below is a summary of some of the thinking behind the development of the model.

To sustain process variations and obtain desirable chemistry conditions it is necessary to have the right and homogenous temperature at the inlet, near the slag and at the outlet. The regions of homogeneity should be as large as possible. The temperature field is strongly influenced by the velocity field. Near the outlet, the velocity field has to be as vertical and symmetric as possible to prevent clogging. Near the steel/slag interface, the transport should be almost horizontal and calm. This can be attained by using flow guides to redesign the flow field.

The consideration of refractory, slag and flux makes it possible to do conjugate heat-transfer calculations right out to the surfaces. Heat conducted to the outermost surface can be heat-exchanged to the surroundings. This is modelled by using temperature-dependent radiative and convective boundary conditions resulting in a physically more correct solution. Solidification at cold parts of the innermost surfaces can be considered in the models. Refractory surfaces suffering from erosion and/or dissolution might be taken into account. Including the refractory in the calculation would also be advantageous in that it would make it possible to use IR techniques for some validation purposes.

The mixing of slag and metal in a zone where the velocities are low is thought to originate from the 
instability that arises when 2 streams of fluid, with stable density differences, flow past one another. The presence of shear leads to instability, which is characterised by the growth of waves, later rolling up into (small) vortices. This shear instability, 'The Kelvin-Helmholtz Instability', may serve as the mechanism of mixing between the layers, promoting the vertical transport of properties such as heat or reactants. Furthermore, Spalding \& Villasenor [16] have shown by using a long duct of a rectangular cross section and 2 fluids of different densities, that this instability could be predicted with a fluid-flow calculation if the position of the interface was calculated. Using these ideas as the basis for the modelling approach, a mathematical model of continuouscasting tundish could be extended to include the slag phase. This development enables predictions of fluidflow and heat-transfer conditions in the highly important steel/slag region.

\section{Conservation equations}

The model is steady or unsteady and is based on conservation equations for the following:

Conservation of mass

$\frac{\partial \rho}{\partial t}+\nabla \cdot(\rho \vec{V})=0$

where $\rho$ is density and $\vec{V}$ is velocity.

Conservation of momentum

$\rho \cdot \frac{\mathrm{D} \vec{V}}{\mathrm{D} t}=-\nabla P+\vec{B}+\mu \cdot \nabla^{2} \vec{V}$

where $P$ is pressure, $B$ is volume force and $\mu$ is dynamic viscosity.

Conservation of energy

$$
\begin{gathered}
\rho \cdot \frac{\mathrm{D} e}{\mathrm{D} t}-\nabla \cdot k \nabla T-\nabla \cdot\left(\sum_{j} \rho D_{j} \cdot e_{j} \cdot \nabla m_{j}\right) \\
-\mu \cdot \Phi-\frac{\mathrm{D} P}{\mathrm{D} t}-S=0,
\end{gathered}
$$

where $e$ is the static enthalpy, $k$ is the thermal conductivity, $T$ the absolute temperature, $\mu$ is the dynamic viscosity, $S$ is the source function (i.e. the thermal energy created per unit volume) and

$\Phi=\left(\frac{\partial u_{i}}{\partial x_{j}}+\frac{\partial u_{j}}{\partial x_{i}}-\frac{2}{3} \frac{\partial u_{1}}{\partial x_{1}} \delta_{i j}\right) \frac{\partial u_{i}}{\partial x_{j}}$

is the dissipation function. The first and last term in the dissipation function within the brackets come from the viscous part of the normal stresses, whereas the second term comes from the shear stresses.
Conservation of elements in each phase

$\rho \cdot \vec{V} \cdot \frac{\mathrm{D} n_{\alpha}}{\mathrm{D} t}=\nabla \cdot\left(\sum_{j} \rho D_{j} \cdot n_{\alpha, j} \cdot \nabla m_{j}\right)$,

where $n_{\alpha}$ is the mass fraction of element $\alpha$ in mixture of compounds, $D_{j}$ is the mass diffusion coefficient for component $j, n_{\alpha, j}$ is the mass fraction of element $\alpha$ in a compound substance $j$ and $m_{j}$ is the mass fraction (concentration) of substance $j$ in mixture.

Turbulent transport equations. The LVEL algebraic turbulence model is a unique feature (built into PHOENICS) useful for conjugate-heat-transfer problems. Far away from the wall, it reduces to the well-established result [18]:

$v^{+}=K \cdot y^{+}$,

where $v^{+}$is the dimensionless effective viscosity, $K$ is the von Karman constant (0.417) and $y^{+}$is the dimensionless distance from the wall.

\section{Auxiliary equations}

Property variations of the steel phase

Density. The temperature-dependent density of steel is described by the following expression [19]:

$\rho_{1}=8.586 \cdot 10^{3}-0.8567 T_{1}$,

where $T_{1}$ is the temperature of the steel.

Heat capacity. The temperature-dependent heat capacity is calculated as [20]

$C_{p, \mathrm{Fe}}=\left(452.963+176.704 \cdot 10^{-3} T_{1}-\frac{482.082 \cdot 10^{5}}{T_{1}^{2}}\right)$.

Dynamic viscosity. The temperature-dependent dynamic viscosity is calculated as [19]

$\mu_{1,1}=0.3147 \cdot 10^{-3} \exp \left(\frac{46480}{8.3144 T_{1}}\right)$,

where $T_{1}$ is the temperature of the steel.

Property variations of the liquid slag phase The following typical slag composition was chosen for the calculations: $50 \% \mathrm{CaO}, 12.5 \% \mathrm{Al}_{2} \mathrm{O}_{3}, 7.5 \% \mathrm{MgO}$ and $30 \% \mathrm{SiO}_{2}$.

Heat capacity. The temperature-dependent heat capacity for slag is calculated as [21]

$$
\begin{aligned}
C_{p, \mathrm{CaO}}= & \frac{4.1868 \cdot 10^{3}}{56.079}\left(11.86+1.08 \cdot 10^{-3} T_{\mathrm{s}}\right. \\
& \left.-\frac{1.66 \cdot 10^{5}}{T_{\mathrm{s}}^{2}}\right)
\end{aligned}
$$




$$
\begin{aligned}
C_{p, \mathrm{Al}_{2} \mathrm{O}_{3}}= & \frac{4.1868 \cdot 10^{3}}{101.961}\left(28.804+2.197 \cdot 10^{-3} T_{\mathrm{s}}\right. \\
& \left.-\frac{11.56 \cdot 10^{5}}{T_{\mathrm{s}}^{2}}\right),
\end{aligned}
$$$$
C_{p, \mathrm{SiO}_{2}}=\frac{4.1868 \cdot 10^{3}}{60.084}\left(17.119+0.452 \cdot 10^{-3} T_{\mathrm{s}}\right.
$$$$
\left.-\frac{9.335 \cdot 10^{5}}{T_{\mathrm{s}}^{2}}\right)
$$$$
C_{p, \mathrm{MgO}}=\frac{4.1868 \cdot 10^{3}}{40.304}\left(11.707+0.751 \cdot 10^{-3} T_{\mathrm{s}}\right.
$$$$
\left.-\frac{2.734 \cdot 10^{5}}{T_{\mathrm{s}}^{2}}\right)
$$

$$
\begin{aligned}
C p_{\mathrm{s}}= & (\% \mathrm{CaO}) C_{p, \mathrm{CaO}}+\left(\% \mathrm{Al}_{2} \mathrm{O}_{3}\right) C_{p, \mathrm{Al}_{2} \mathrm{O}_{3}} \\
& +(\% \mathrm{MgO}) C_{p, \mathrm{MgO}}+\left(\% \mathrm{SiO}_{2}\right) C_{p, \mathrm{SiO}_{2}},
\end{aligned}
$$

where $T_{\mathrm{s}}$ is the temperature of the slag.

Dynamic viscosity. The temperature dependence of the dynamic viscosity for the slag is given by the following expression [22]:

$\mu_{1, \mathrm{~s}}=1.0 \cdot \exp \left(-5.589+\frac{24323.7}{T_{\mathrm{s}}}-0.7099 \cdot \ln \left(T_{\mathrm{s}}\right)\right)$

where $T_{\mathrm{s}}$ is slag temperature.

Treatment of the liquid slag phase

General equations. Incorporation of the slag phase into the model of the tundish has been carried out by using the following 2 equations [23-26]:

$$
\frac{\partial}{\partial t}\left(\rho_{1} c_{1}\right)+\operatorname{div}\left(\rho_{1} \vec{V}_{1} c_{1}\right)=0,
$$

$\frac{\partial}{\partial t}\left(\rho_{\mathrm{s}} \mathcal{C}_{\mathrm{s}}\right)+\operatorname{div}\left(\rho_{\mathrm{s}} \vec{V}_{\mathrm{s}} \mathcal{C}_{\mathrm{s}}\right)=0$,

where $\vec{V}_{1}$ is the velocity vector for the steel phase and $\vec{V}_{\mathrm{s}}$ is the velocity for the slag phase. The variable $c_{1}$ has, at time 0 , the value 1 in the regions where there is only steel and has the value 0 in the regions where initially there is only slag. Similarly, $c_{\mathrm{s}}$ has the values 0 and 1 in the regions where the tundish initially contains only steel and slag, respectively. The volume of steel per unit mass, $V_{\text {st }}$, and the volume of slag per unit mass, $V_{\text {sl }}$, are calculated as follows [23]:

$V_{\mathrm{st}}=\frac{c_{1}}{c_{1}+c_{\mathrm{s}}} \frac{1}{\rho_{\mathrm{st}}}$,
$V_{\mathrm{sl}}=\frac{c_{\mathrm{s}}}{c_{1}+c_{\mathrm{s}}} \frac{1}{\rho_{\mathrm{sl}}}$,

where $\rho_{\mathrm{sl}}$ is the density of the slag and $\rho_{\mathrm{st}}$ is the density of steel. The total volume of the liquid phase (steel and slag) per unit mass is given by [23]

$V_{\mathrm{tot}}=V_{\mathrm{st}}+V_{\mathrm{sl}}$.

Treatment of the solid slag phase (flux). The computational area where covering powder blocks the flow is set to have the following physical properties [27]:

$\begin{array}{ll}\text { density } & 600 \mathrm{~kg} / \mathrm{m}^{3} \\ \text { specific heat } & 1180 \mathrm{~J} / \mathrm{kg}^{\circ} \mathrm{K} \\ \text { thermal conductivity } & 1.7 \mathrm{~W} / \mathrm{m}^{\circ} \mathrm{K} \\ \text { hermal expansion } & 0\end{array}$

\section{Boundary conditions}

The most decisive boundary conditions for a solution are given below.

The fixed mass flow at the inlet. The mass flux at the inlet is the product of the velocity $(\mathrm{m} / \mathrm{s})$ and the density $\left(\mathrm{kg} / \mathrm{m}^{3}\right)$ usually set in the first cell layer.

The constant pressure at the outlet. At the outlet, the desired pressure normally is the dynamic pressure. Therefore it is convenient to set the reference pressure to 0 .

The frictional flow near the lining. At the fluid/solid interfaces fully developed friction is set.

The emissivities and heat-transfer coefficients for slag and tundish surfaces. The heat transfer takes part both through the lining and through the flux. The lining is usually 4-layered and results in the following expression:

$\theta_{\mathrm{s}}-\theta_{\mathrm{g}}=\frac{1}{k} \cdot \frac{\phi}{A} \quad \frac{1}{k}=\frac{1}{\alpha_{\mathrm{s}}}+\sum_{1}^{\mathrm{n}} \frac{\delta_{\mathrm{i}}}{\lambda_{\mathrm{i}}}+\frac{1}{\alpha_{\mathrm{g}}}$

where $\theta_{\mathrm{x}}$ is temperature at different layers ( $\mathrm{s}$ is steel, $\mathrm{g}$ is surrounding gas), $\mathrm{k}$ is heat transmission coefficient, $\alpha_{\mathrm{s}}$ and $\alpha_{\mathrm{g}}$ are heat-transfer coefficients at steel-refractory and outer surfaces respectively $\left(\mathrm{W} / \mathrm{m}^{2}{ }^{\circ} \mathrm{C}\right), \delta_{\mathrm{i}}$ is thickness of layer $\mathrm{i}(\mathrm{m}), \lambda_{\mathrm{i}}$ is thermal conductivity for material $\mathrm{i}\left(\mathrm{W} / \mathrm{m}{ }^{\circ} \mathrm{C}\right), \phi$ is heat flow rate $(\mathrm{W})$ and $A$ is the area of conducting cross section $\left(\mathrm{m}^{2}\right)$.

The heat energy entering the outer surfaces is heatexchanged to the surrounding through 3 mechanisms:

$\varphi=\varphi_{\mathrm{gs}}+\varphi_{\mathrm{sw}}+\varphi_{\mathrm{c}} \quad\left(\mathrm{W} / \mathrm{m}^{2}\right)$

where $\varphi_{\text {gs }}$ is radiation exchange with radiating gas volume (can be neglected), $\varphi_{\mathrm{sw}}$ is radiation exchange with tundish walls, ladle bottom and surrounding walls and $\varphi_{\mathrm{c}}$ is natural convection with the gas near the tundish walls. 
In case the ladle bottom or other parts of reactors are warmer than the flux surface, then a positive heat exchange to the tundish will take place.

Radiation exchange. The radiation exchange is given by the formula below [28]:

$\varphi_{\mathrm{sw}}=\sigma \cdot \varepsilon_{\mathrm{sw}} \cdot\left(\theta_{\mathrm{s}}^{4}-\theta_{\mathrm{w}}^{4}\right)$

where

$\varepsilon_{\mathrm{sW}}=\varepsilon_{\mathrm{S}} \cdot \varepsilon_{\mathrm{W}} \cdot \tau_{\mathrm{gm}} \cdot \beta_{\mathrm{sW}}+\Delta \varepsilon_{\mathrm{sW}}$

and where $\sigma$ is Stefan-Boltzman's constant $\left(\mathrm{W} / \mathrm{m}^{2} \mathrm{~K}^{4}\right)$, $\epsilon_{\mathrm{s}}$ is the emissivities for flux and tundish walls, $\epsilon_{\mathrm{w}}$ is the emissivities for influencing walls, $\tau_{\mathrm{gm}}$ is $1-A_{\mathrm{gm}}$ (can be set to 1 in air and in the absence of flames), $A_{\mathrm{gm}}$ is the mean absorption number for surrounding gas due to radiation from the surfaces, $\beta_{\mathrm{sw}}$ is the view factor (=1 at plane and not shadowed surfaces), $\Delta \epsilon_{\mathrm{sw}}$ is flame radiation contribution (can be neglected), $\theta_{\mathrm{s}}$ is surface temperature.

Convective exchange. The convective exchange regards the heat exchange to the gas near the surfaces of the tundish, the shroud, the SEN and also the flux surface. The exchange is taken to occur as natural or slightly forced convection. The mathematical expression is

$\varphi_{\mathrm{c}}=\alpha_{\mathrm{s}} \cdot\left(\theta_{\mathrm{g}}+\Delta \theta_{\mathrm{g}}-\theta_{\mathrm{s}}\right)$,

where $\alpha_{\mathrm{s}}$ is convective heat-transfer coefficient (W/ $\mathrm{m}^{2}{ }^{\circ} \mathrm{C}$ ) and $\Delta \theta_{\mathrm{g}}$ is $\theta_{\mathrm{g}}$ (measure point) minus $\theta_{\mathrm{g}}$ (near surface).

The emissivities are measured with thermovisioncamera to around 0.85 for the flux and to ca. 0.93 for the outer surfaces of the tundish. The convective heattransfer coefficient is empirically set to $10-15$. The surface losses are than in the range $5-25 \mathrm{~kW} / \mathrm{m}^{2}$.

Simple measurements with spot-meter or contactpyrometer ought to be enough for verification. For more exact validation, a measurement with thermovisioncamera is preferred.

\section{Solution}

The commercial, sequential or parallel program [29], PHOENICS is used to solve the mathematical equations. A well-posed problem is usually solved within $10-30 \mathrm{~h}$ with 1 CPU. The elapsed time can be reduced to $4-12 \mathrm{~h}$ with 3 CPUs.

\section{Numerical method}

The grids are developed as Multi-Block-Fine Grid Embedded (MBFGE) grids [18]. The main grid can be divided in parts and specific objects can have a finer grid. Though the staggered-grid method is the most common, the Collocated Covariant Method (CCM) and Generalised Collocated Velocity (GCV) method are also used, the former especially in conjunction with the LengthVelocity (LVEL) model. The effective viscosity calculation in the LVEL model [18] is based on the distance from the nearest wall, the local velocity and the laminar viscosity. In the GCV method, structured grids are linked in an unstructured way. This method is used in cases where grid-influenced convergence is undesirable.

\section{Initial conditions}

Initially, the species content for each cell is defined in an input file, as well as the physical and/or metallurgical properties. Solved for variables are given expected values in the entire calculation domain.

\section{Convergence criteria}

The number of sweeps guided the convergence. The number of sweeps was adjusted to be large enough to give the last change of all values less than $10^{-3}-10^{-4}$ times the value itself. Usually $1500-2500$ sweeps were necessary to fulfil the criteria.

\section{Flow and temperature field results}

Almost all of the properties of steel, slag and refractory are temperature dependent. Therefore a good prediction of temperature is necessary for reliable predictions of other quantities. The flow field in a tundish strongly influences the temperature field. Earlier studies were aimed at verifying predictions [2] of both the fluid-flow and the temperature fields. However, the flow-field verifications were rather expensive. Infrared temperature measurements on the outer surfaces and the observation of hot spots have instead often been relied upon for verification purposes. The hot spots indicate that the fluid flow is hitting the surface more or less perpendicularly at those positions, thus giving an indication of the flow field (Fig. 1).

\section{Prediction}

Fig. 2 shows how the flow field modified by weirs results in an improved temperature distribution. A baffle prevents the re-circulating of colder steel on its way towards the inlet. The result is a uniform high temperature at the inlet and instead of a 10-20-degree temperature gradient at the outlet, a homogeneous and symmetric temperature distribution in 3 dimensions is achieved. The temperature at the steel/slag interface is also improved with respect to chemical reactions.

At the end of each heat the velocity field at the inlet (Fig. 2) enhances the removal of slag particles dispersed in the steel. The removal of slag is furthermore 


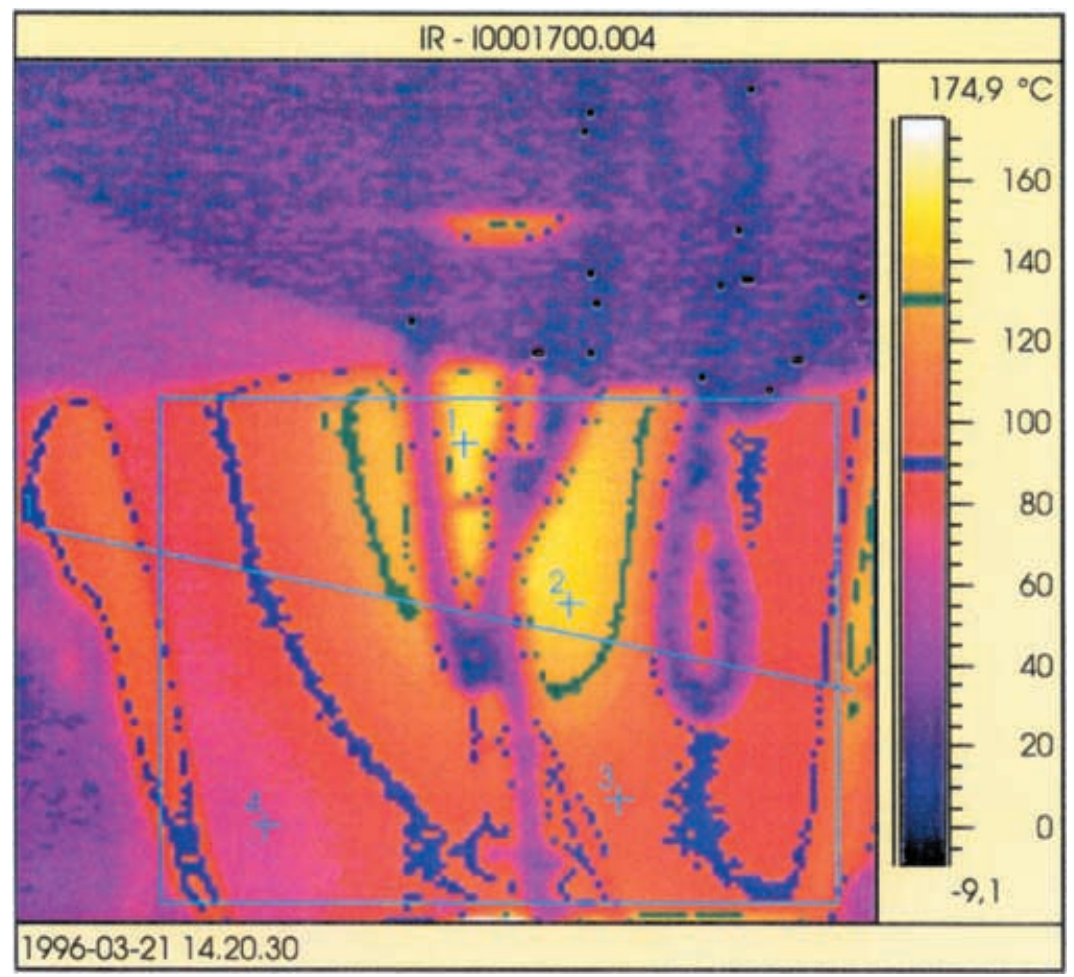

a

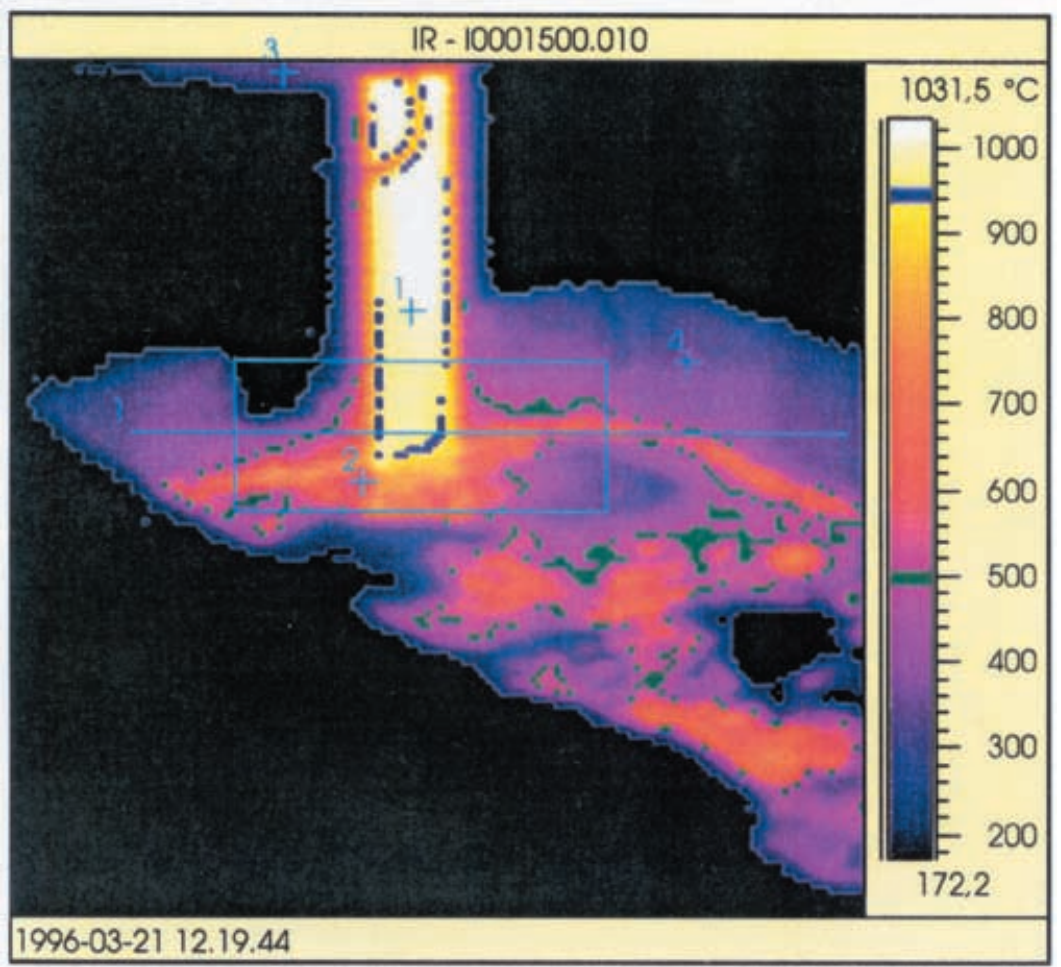

b

Fig. 1. (a) An infrared picture showing surface temperatures and hot spots on the plate surface at the outlet end of a tundish; (b) an infrared picture showing temperatures on flux, ladle shroud and hot spots.

facilitated by the use of the turbulence killer and the small dam. This results in a modified momentum in the vertical direction, which in addition to the rising of the slag velocity according to the Stoke's equation pro- motes slag flotation. Also, the calm passage at the steel/slag interface makes it probable that only a small amount of slag penetrates into the steel flow (cf. section on slag flotation and entrapment results). Finally, at the 


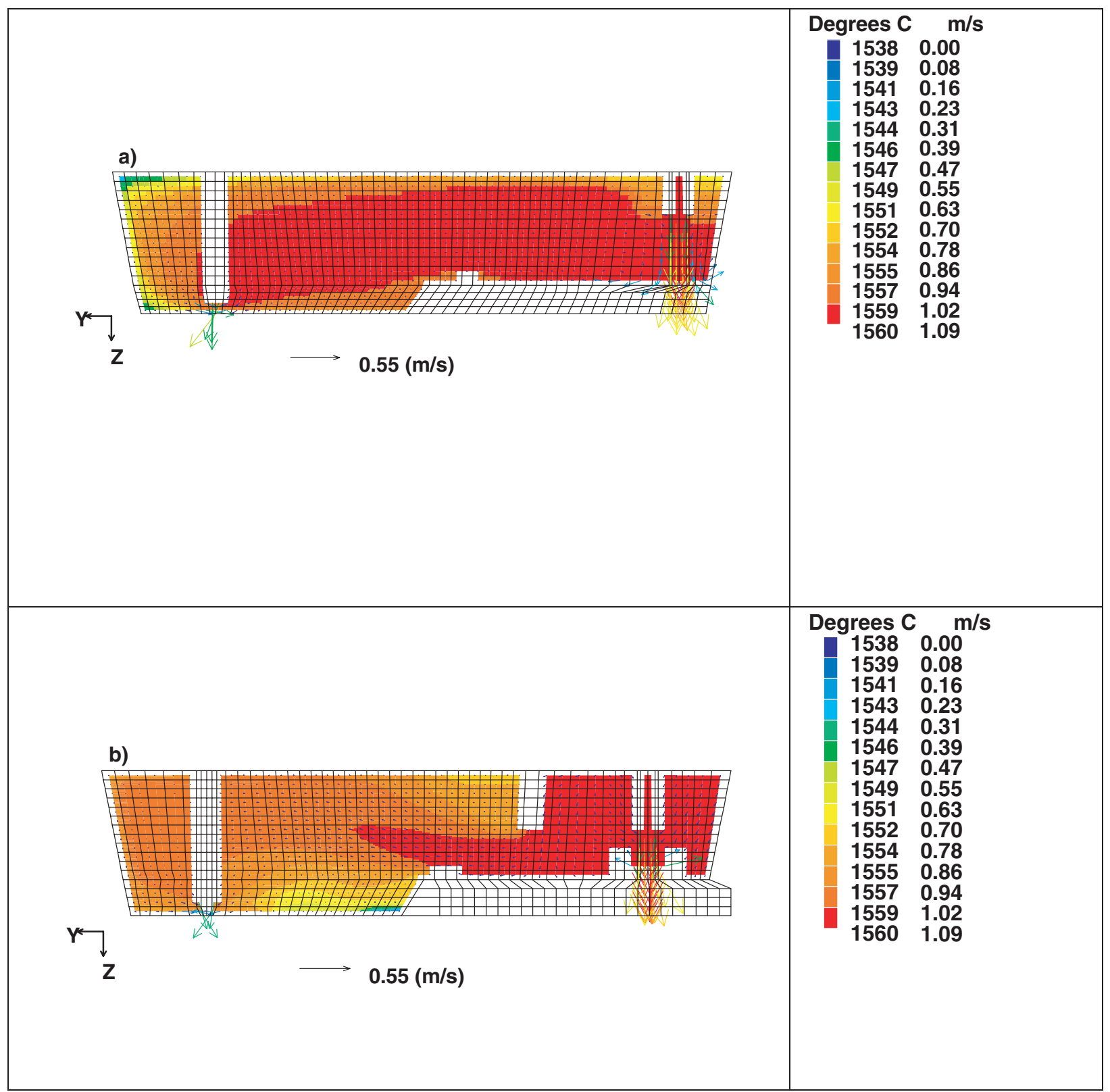

Fig. 2. Velocity vectors superimposed on temperature profiles of (a) a normal praxis and (b) a modification of the flow field with weirs.

outlet it can be seen that the velocities are fairly vertical and symmetrical around the outlet opening. This is believed to hinder small inclusions from clogging the seat of the SEN and the SEN itself.

Fig. 3 shows temperature contours for a 2-strand tundish in a simulation done after refractory, slag and flux were implemented in the model. Currently both refractory and slag powder are included. Thus, it has become possible to consider solidification at those parts of the tundish wall having a wall temperature below the liquidus temperature.

\section{Verification}

All predicted results are considered unreliable until a model is verified, which is when all predicted entities are verified. Different verification techniques have to be used for different predicted entities.

The thin-film carbon-rod technique [30] was used to verify the velocity field. Finding a good measurement position was a difficult task but with guidance by means of the prediction it was possible to find a homogeneous non-turbulent position. Another difficulty was obtaining a correct calibration of the rods for the lowvelocity conditions in near-laminar measurement positions. Fig. 4 shows measured and predicted velocities as a function of depth between the slag and the bottom of a tundish in such a position. The thin-film theory is not adequate for velocities under $1 \mathrm{~cm} / \mathrm{s}$ (which is the limit of the calibration). That is why the agreement is not so good just below the slag and just above the bottom. 


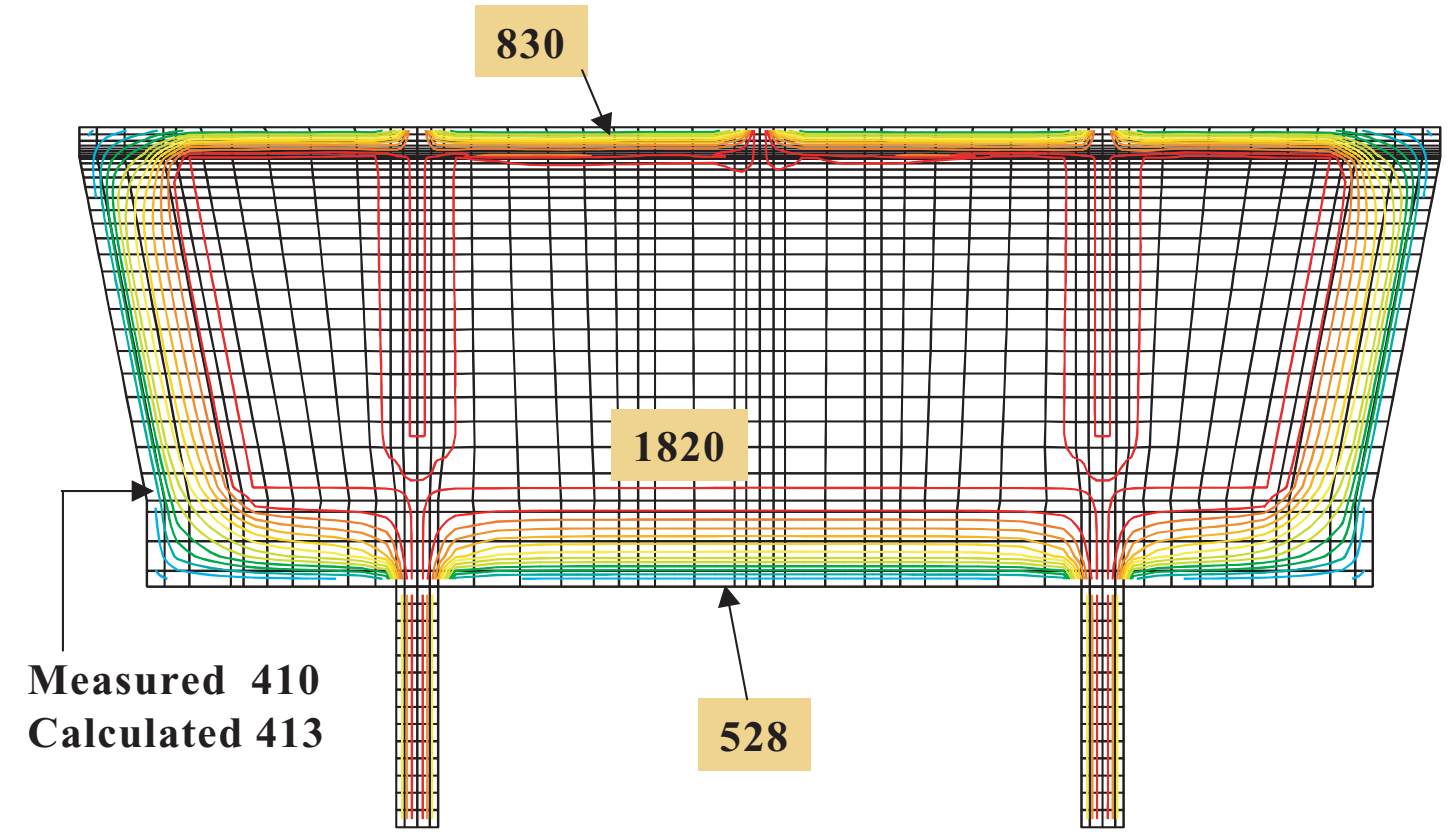

Fig. 3. Isotherms in slag, powder and refractory in a 2-strand tundish and also in the 2 SENs.

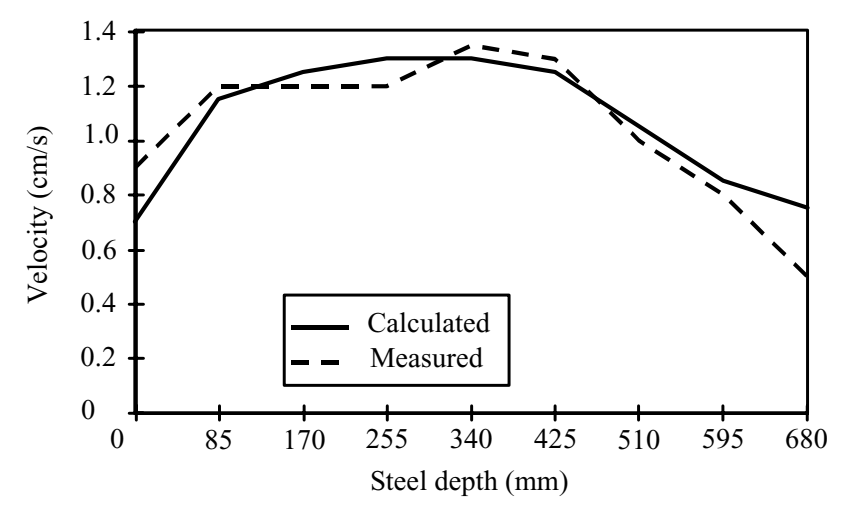

Fig. 4. Predicted and measured steel velocities as a function of steel depth.

The best agreement between predictions and measurements would be achieved if the rods were included in the simulation model and a one-sided comparison was made.

Thermocouples of almost equal calibration were selected for the temperature-field measurements, both in the fluid and in the refractory. The temperature is shown in Fig. 5 at 3 depths, approximately $10 \mathrm{~cm}$ inside the fluid. Because the refractory and slag powder have been included in the model, it has been much easier to verify both temperature and velocity models. As mentioned above, this can now be done by direct measurement of emissivities, surface temperatures and observation of hot spots.

Near-stationary temperature profiles in different refractory layers could also be measured by installing a number of thermocouples inside the lining. In Fig. 6 the measured temperatures are compared with the corresponding predictions.

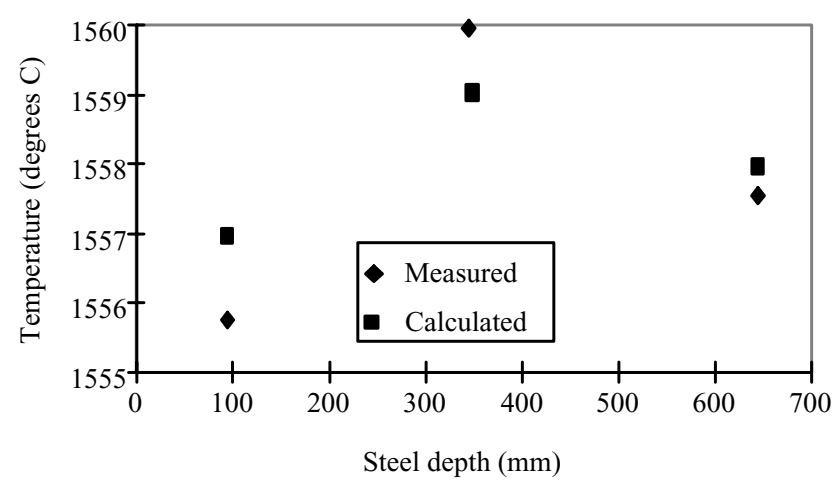

Fig.5. Predicted and measured steel temperatures as a function of steel depth.

When both velocities and temperatures are verified the question arises of whether the calculations could be used to enhance the design of the tundish in such a way that the steel quality is improved. Figs. $7 a$ and $b$ show how the production praxis is influenced. Fig. 7c indicates that the steel cleanness, based on total oxygen analyses, is improved by $10 \mathrm{ppm}$. The difficulty was to get the samplers to take samples in the same way, i.e. the

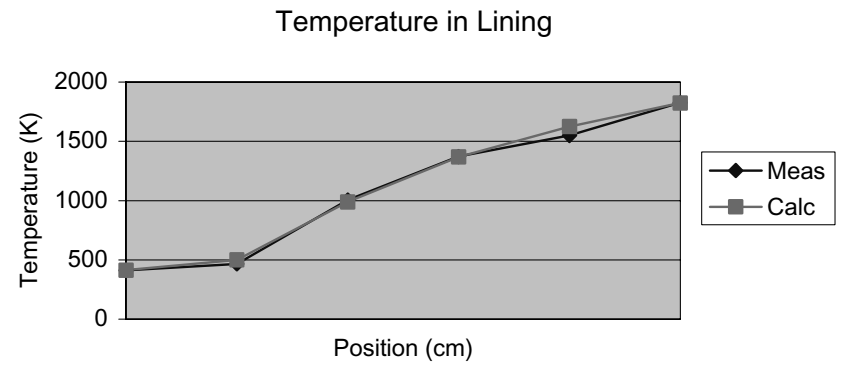

Fig. 6. Measured and calculated temperatures in the refractory as function of position in the lining. 

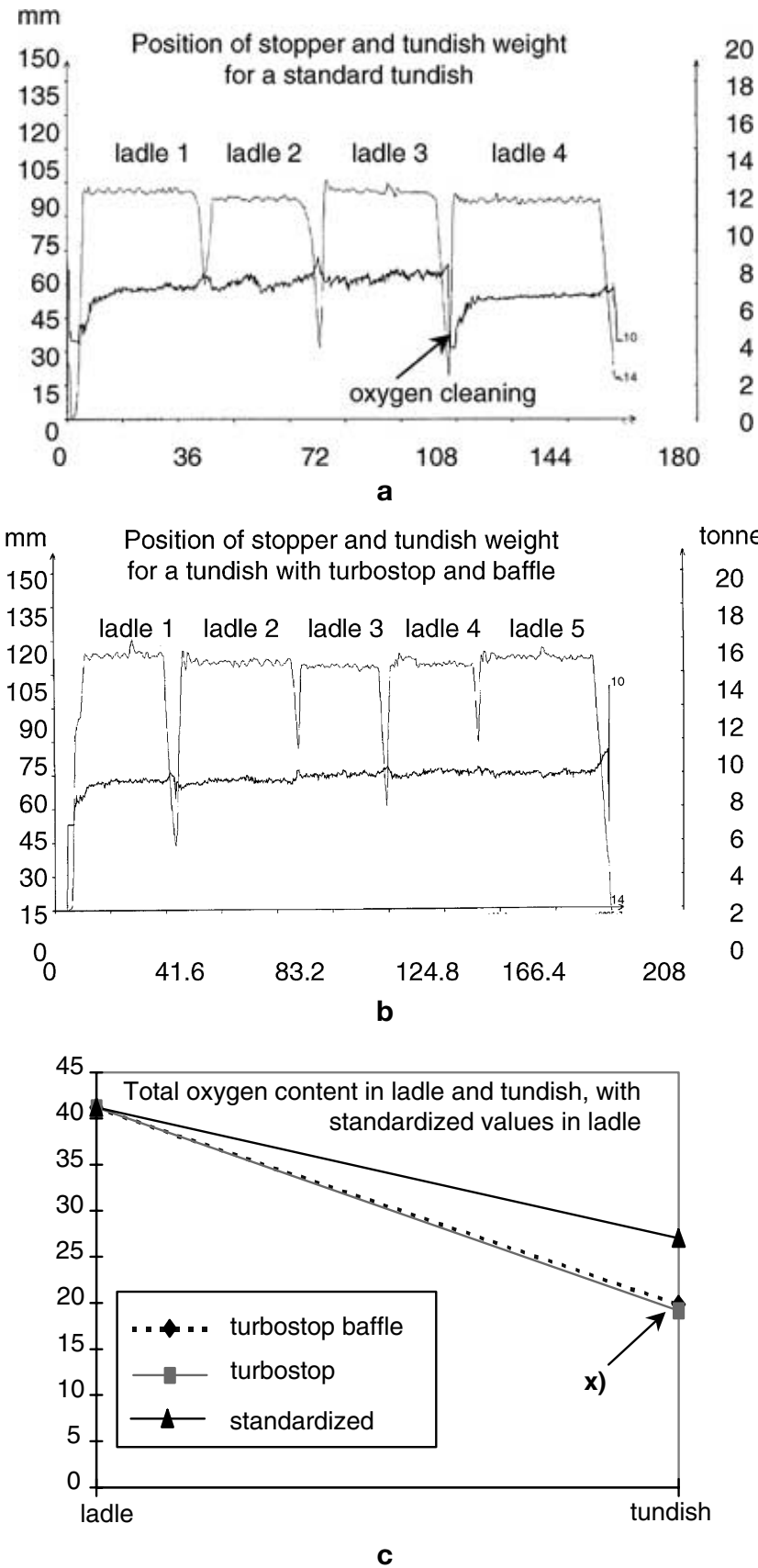

Fig. 7. (a) Heat changes and stopper rod movement during casting in a normal praxis tundish; (b) heat changes and stopper rod movement during casting in a modified tundish; (c) steel cleanness in the tundish relative to steel cleanness in the ladle for both standard and modified tundish.?

reproducibility. To be fully convinced more appropriate experiments have to be done.

Figs. 8 and 9 probably show an indigenous slag being built upon an exogenous nucleus. Apparently, larger slag particles are floating up whilst small ones follow the steel flow.

\section{Slag flotation and entrapment results}

The slag/steel-mixing zone is a mixture between the tundish slag and exogenous ladle slag, floated ex-

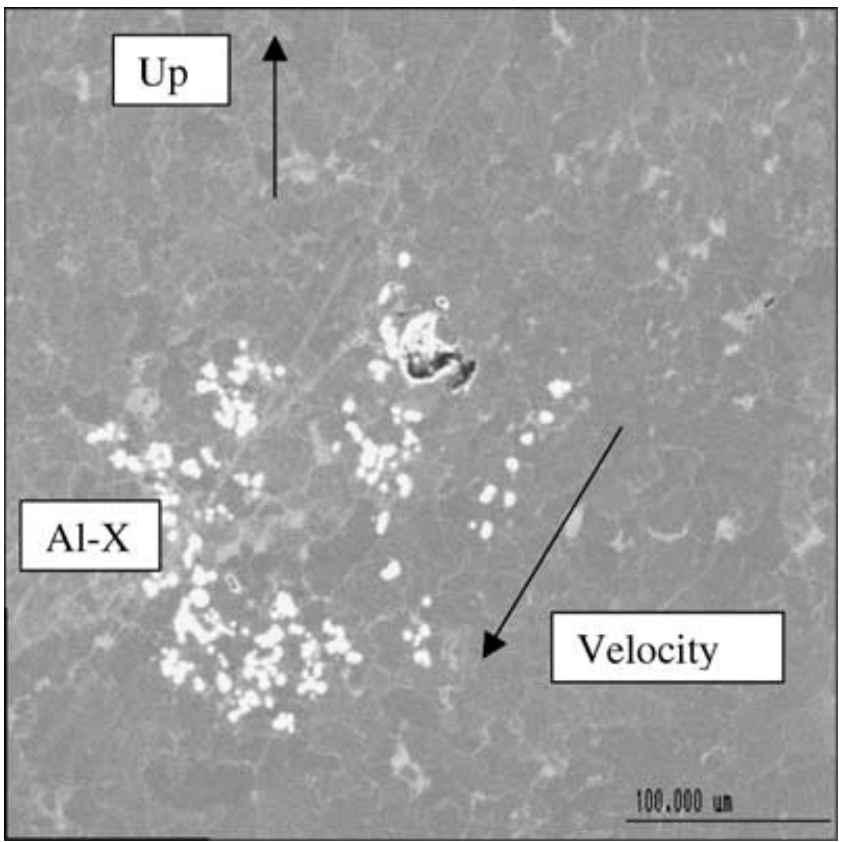

Fig. 8. Rapidly rising, $\sim 30-\mu m$ large, 'unstable' slag in low-carbon steel surrounded by small $(<2 \mu \mathrm{m}) \mathrm{CaAl}-\mathrm{AlO}$ slag particles following the flow field approximately $8 \mathrm{~mm}$ below the steel/slag interface.

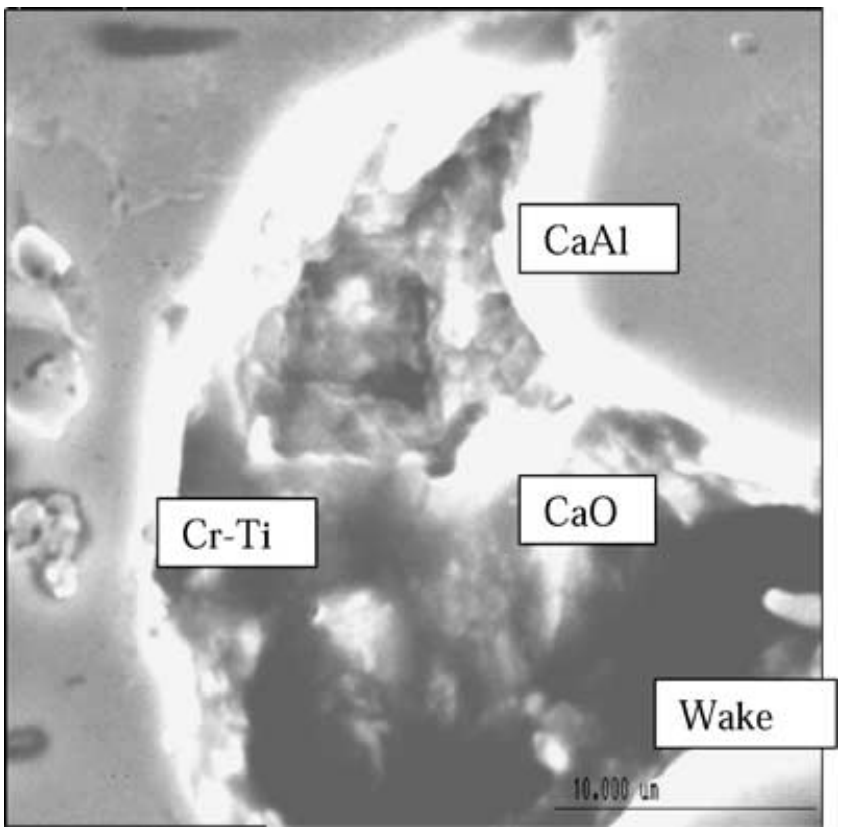

Fig. 9. Detailed structure of the rising particle being an indigenous slag built on an exogenous Cr-Ti nucleus.

ogenous and/or indigenous inclusions as well as the tundish steel including rising inclusions. The fluid flow is physically governed by the equations in the section on mathematical modelling. The variables solved are the concentration variables representing slag and steel. The predicted values should be comparable with a momentary flow-field situation. Also, it should be possible to identify the mixing mechanisms at the interface from the samples taken. 


\section{Prediction}

First a preliminary solution was obtained with a reasonable converged velocity field without solving for the concentration variables governing the flow in the slag/steel-mixing zone. Thereafter, the full solution was obtained by restarting from the preliminary solution.

Fig. 10 shows the predicted slag concentration in steel below the slag layer. The situation next to the ladle shroud penetrating into the tundish is interesting. It can be seen that the concentration profile follows the flow field, indicating that slag is pulled down by the down flow. The figure also indicated that slag fringes may transport slag to the incoming downwardly directed high-velocity flow. This transport probably results in some entrapment of slag droplets.

Fig. 11 shows the slag concentration in the uppermost steel layer ( $3 \mathrm{~mm}$ down in steel). The figure further indicates that slag, though low in concentration, penetrates into the steel as a result of the velocity field. Near the walls, the upwardly flowing steel instead pushes steel towards the slag. Along the symmetry plane, near the stopper rods and near the ladle shroud, there are downwardly directed velocity components facilitating the downward transport of slag.
A reasonable question is how it is possible at all for penetration of slag into steel to occur at these low, almost horizontal, velocities (cf. subsection SEM studies).

\section{Measurements}

The slag model, being a fairly new model component, puts new demands on the verification technique and analyses. The interpretation of the concentration distribution revealed suitable positions for sampling. However, sampling at the steel/slag and steel/refractory interfaces is not easy. Inexpensive sampling techniques have so far not been reported. Therefore, a simple reuseable sampler MISS (Momentary Interfacial Solidification Sampling) was developed and used for lowcarbon steel grades. Based on old and new ideas, efforts have also been made to develop a suitable analysis technique.

Sampler and sampling. The sampler is described in an internal MEFOS report [17]. Mainly it consists of a 120 -mm long square $(8 \times 80 \mathrm{~mm})$ pipe with a mass that ensures adequate cooling. Because the sample should not be heated, the sampler must be properly insulated. Moreover, to avoid turbulence at the surface of the

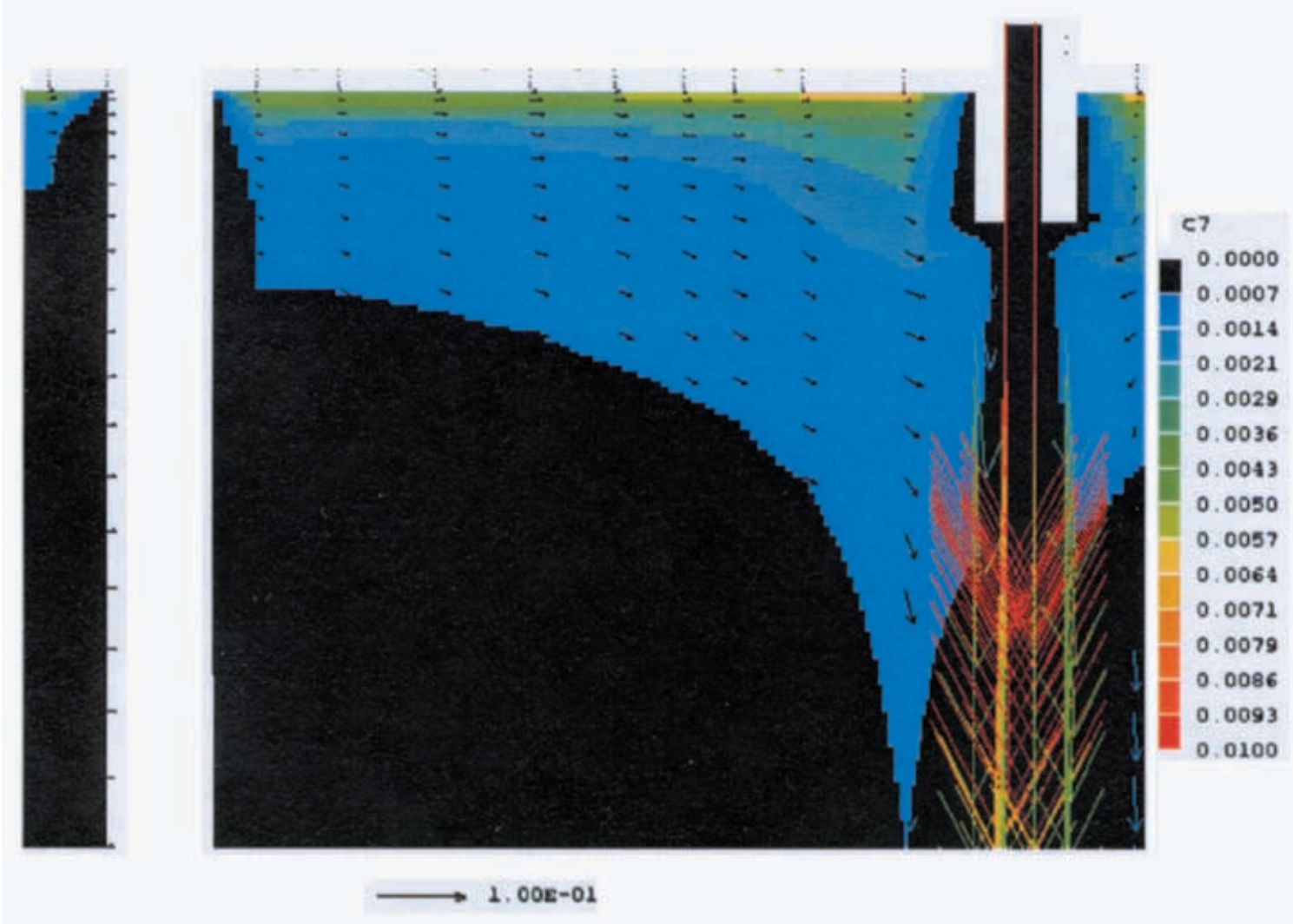

Fig. 10. Velocity vectors superimposed on slag concentration profiles in the steel domain. Higher concentrations are found just below the steel/slag interface and where velocities have downwardly directed components. 

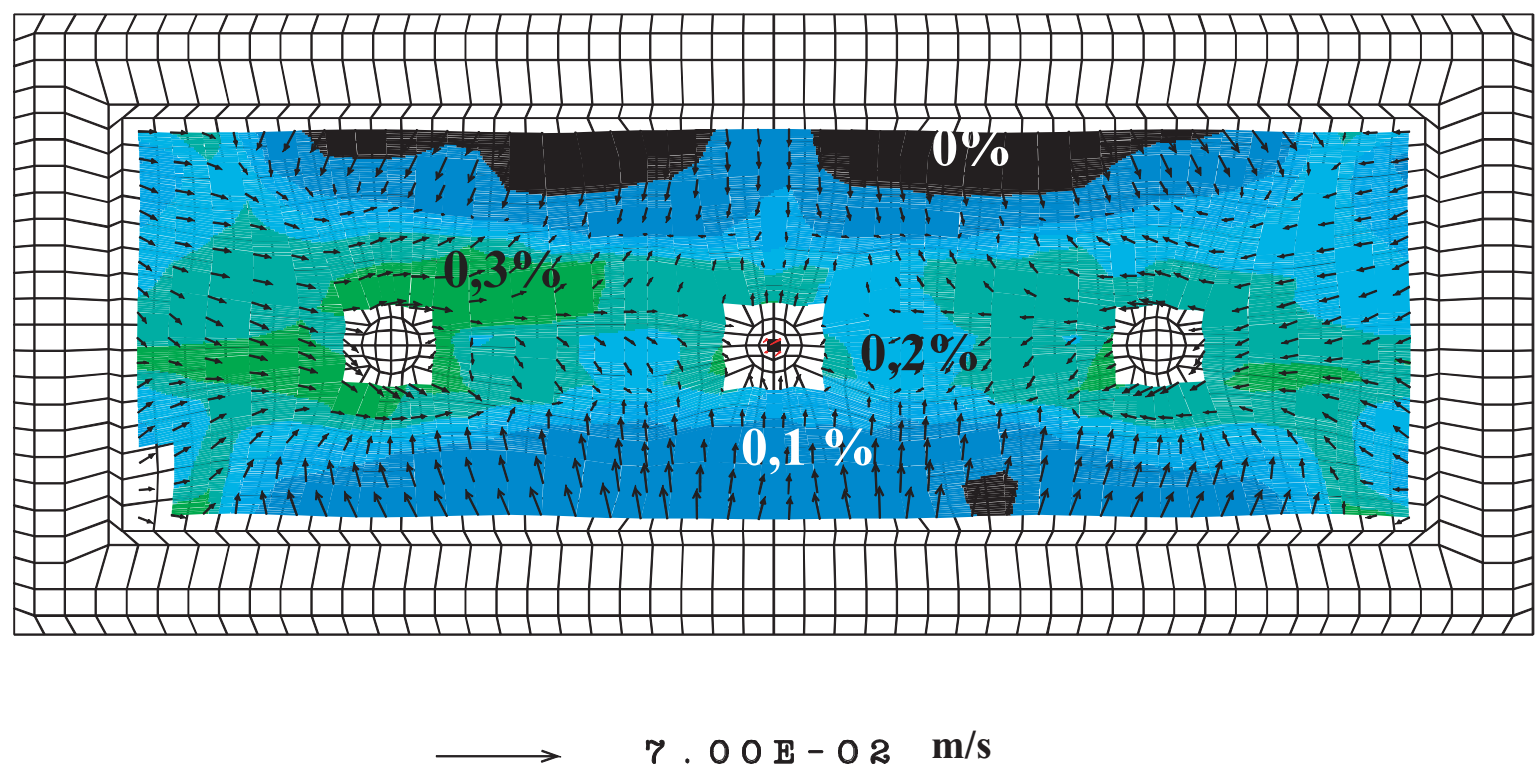

Fig. 11. Slag concentrations in the upermost steel layer (3-mm thick). In regions where the flow is upwards (black) the concentration is very low, indicating that steel is being pushed upwards.

sample, the interior must be etched for good wetting conditions.

When the sampler is immersed into the liquid at the correct speed, the result is a flat or slightly convex slag surface. For low-carbon steel $0.5 \mathrm{~s}$ is suitable. After $3-5 \mathrm{~s}$ the sampler is lifted and cooled after which the sample is released.

Sample preparation and ultrasonic study. The samples are heat-treated to obtain good structural homogeneity. Surfaces are machined plane parallel. The entrance surface should be machined very well.

Ultrasonic immersion testing techniques are used to analyse the samples. The instrument used for this study is a Branson Krautkramer USIP20HR with a highfrequency option. The probe frequency is $50 \mathrm{MHz}$ with a $0.5^{\prime \prime}$ focal length (in water). 2 flat-bottom holes (FBH) of 70 and $50 \mu \mathrm{m}$ were used for calibration. This instrument consists of a high-frequency point-focused probe, an immersion tank with an X-Y scanning-probe and a PC-based data collection and evaluation system. The inspected zone depth is $1.3 \mathrm{~mm}$ in the centre of the sample. The inspection zone is determined by physical properties of the probe and ends in both directions when half of the energy is lost, which happens when the energy drop is $-6 \mathrm{~dB}$ (decibel). The resulting C-scan (the PC image) is then used for evaluation. The evaluation is based upon experience from earlier testing. A-scan and time of flight (instrument screen) is used as a complement to the C-scan during evaluation. In A-scan, porosity often produces multiple peaks while inclusions usually produce a single peak.

The ultrasonic testing is used to get a coarse overview of rising inclusions, penetration of slag particles into

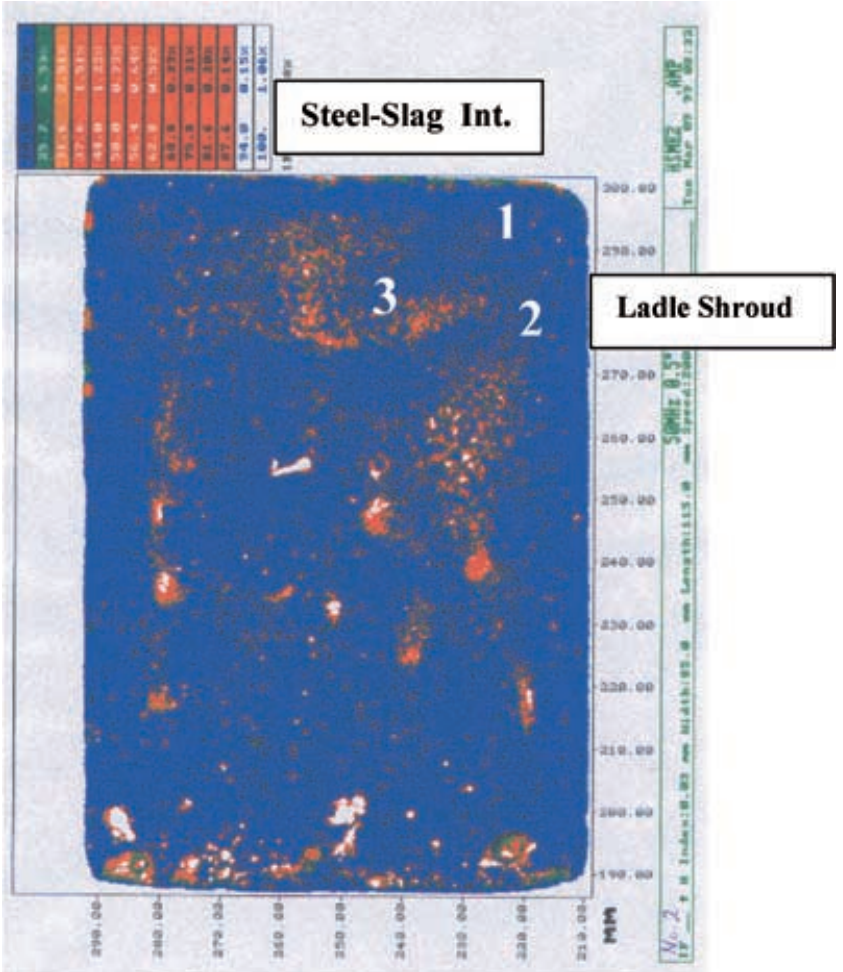

Fig. 12. Image showing the distribution of rising slag particles and entrained slag particles along with the inevitable pores resulting from ultrasonic testing. The $x$-ray analysis positions are marked.

steel and unwanted pores. The entrapped slag particles may also be earlier floated exogenous, indigenous or mixed slags. Fig. 12 shows typical ultrasonic testing results compared with corresponding predicted results. The sample is taken approximately $50 \mathrm{~mm}$ from the surface of the ladle shroud and penetrating $120 \mathrm{~mm}$ down into the steel. Apparent similarities are found with 
respect to the predicted flow and concentration fields (cf. Fig. 10). The upper surface is the steel/slag interface and has a remaining thin slag layer attached to the steel, probably being the mixing zone.

Light-microscope studies. For examination by LOM mainly a Micro-Vickers was used. The purpose was to get an overview of the MISS plates at magnification of $150 \times$ as well as details of different areas at magnification $600 \times$. That equipment is also used for hardness tests. The most important use was the marking of interesting details as inclusions. This was also necessary for location of the object to be examined by AFM. SEM analyses for identification usually preceded this location marking.

SEM studies. These studies are mainly used for analysis of the involved components in regions or within specific inclusions. This is a prerequisite for further examination with the AFM technique.

Fig. 8 shows a rising slag particle indicated by the wake. Probably the inclusion is unstable because smaller alumina particles break off during its path to the top slag. Fig. 9 is the detail of the same inclusion showing how $\mathrm{Ca}-\mathrm{Al}$ and oxides are built on a nucleus of $\mathrm{Cr}-\mathrm{Ti}$.

Fig. 13 is a picture of the steel/slag interface showing significant instability of the slag/metal interface. Fig. 14 is a detail of such an instability. The region was determined to contain salts (Na- and K-salts) and oxides (mainly Fe-, Al-, Si-oxides).

The thin slag layer (mixing zone) was determined to have a large quantity of $\mathrm{Al}$ next to the steel body but also much Fe in higher slag layers as is shown in Fig. 15. This probably indicates the existence of a mixing zone adjacent to the steel body.

Finally, Fig. 16 illustrates $x$-ray mappings of the 3 positions marked in Fig. 12. The maps indicate that there is an increasing content of $\mathrm{Al}$ and $\mathrm{Si}$ from the first position to the third.

AFM studies. The principal of AFM is the same as for most profilometer techniques, a sharp tip scanning the surface collects height data. The primary exception is the highly sensitive positioning mechanism moving the tip or the sample, and the extremely small tips sensing the surface. The most common position technique is the use of a piezo tube for the movement in all directions, $x-y$ and $z$. An $x-y$ motion goes up to about $125 \mu \mathrm{m}$. A $z$-direction motion goes up to around 5-8 $\mu \mathrm{m}$. The tips are usually of pyramidal shape made with the same techniques as integrated circuits. They have a typical radius in the range of $10-50 \mathrm{~nm}$. To be able to scan with such a small tip without breaking it, the force is measured from the bending of a cantilever holding the tip. By sensing the deflection of light from a laser and a 4segmented photodiode (normally), the force can be kept constant. The resolution of the AFM is in the range of a few Ångströms for a crystal-like ordered surface (of course highly dependent on the shape of the tip). For more irregular surfaces, a resolution ranging in the order of 1 to a couple of nanometres is more likely.

The advantage of using AFM is that no special sample preparation is required. The sample can be viewed in vacuum, air, liquid or gas, and it can be non-conductive or conductive. Friction, adhesion, hardness and electric or magnetic properties can be measured besides the topography. The ability to zoom in from macro-scale (125 $\mu \mathrm{m})$ to nanometre scale makes the AFM a very sensitive tool for the study of inclusions and the formation of micro-cracks in steel. Typical images of inclusions in steel can be seen in Figs. 17 and 18.

Fig. 17 shows a MnS inclusion in a perlite structure. Bonds, perpendicular to the surrounding matrix can be seen. The clustered structure of the inclusion is obvious. Fig. 18 is a picture of clustered $\mathrm{Al}$ oxides. The clusters apparently avoid the surrounding matrix, thus creating voids. Bonds are probably found only at positions where the matrix is distorted.

\section{Discussion}

In Figs. 4 and 5, the predictions made by the present model show good agreement comparing measured and predicted velocities and temperature in liquid steel. The statement made by Mazumdar and Guthrie that a reasonable mathematical framework now exists for predicting flow and the associated transport processes therefore appears to apply also for the present model of a continuos casting tundish. In this model, the refractory has been incorporated in the calculation domain to achieve the future possibility to model steel-refractory interaction. As seen in Fig. 6, there was also good agreement between measured and predicted refractory temperatures. With reliable model predictions at hand, a comparative analysis of the effect of different configurations of flow guides in a specific tundish can be done with respect to processes like inclusion floatation merely by studying the predicted flow pattern for each configuration. Demonstrated in Fig. 2 is such an example of the successful use of model predictions to configure flow guides that lead to improved fluid-flow and temperature profiles, thus resulting in a reduction of the total oxygen content $(\approx 10 \mathrm{ppm})$. In summary, in most cases it seems possible to improve inclusion flotation for each specific tundish by choosing a suitable configuration of flow guides determined from inspection of model predictions.

However, a more precise evaluation of the steel cleanness should render a quantitative comparison of 


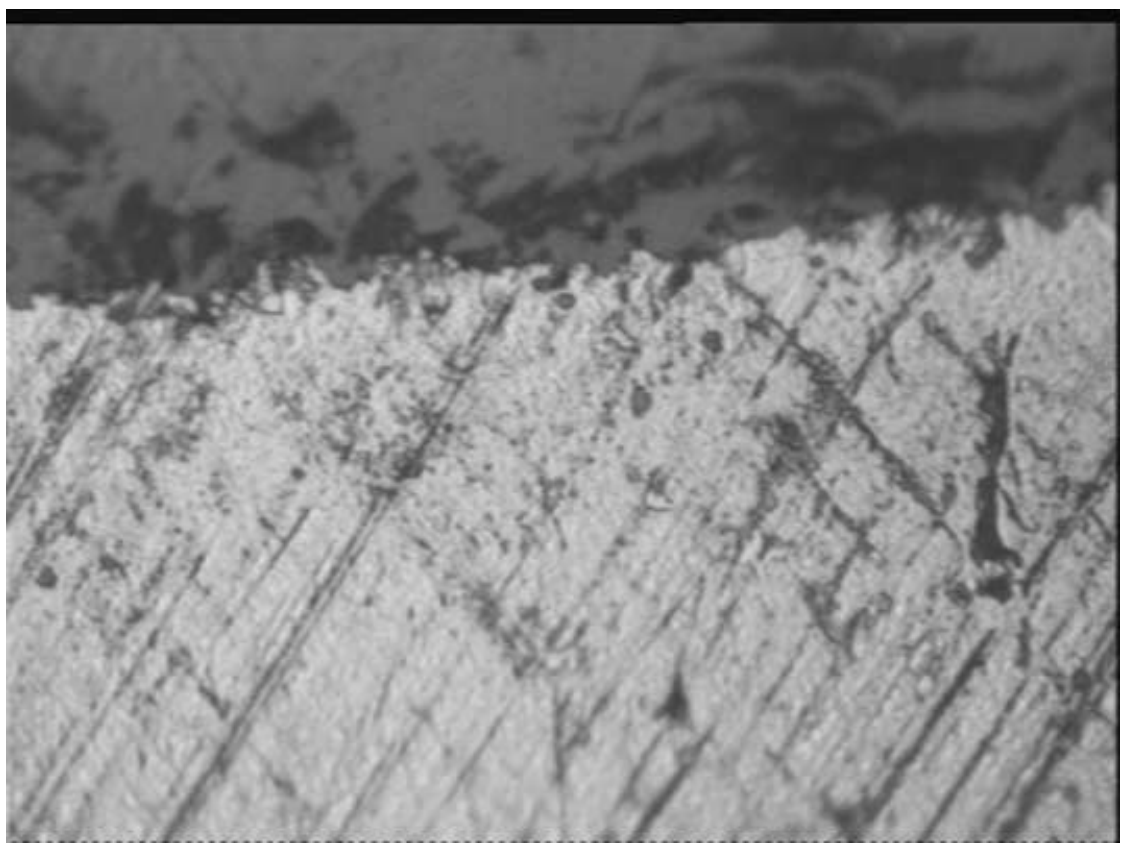

Fig. 13. Instantaneously solidified steel/slag interface showing instabilities in the mixing zone.

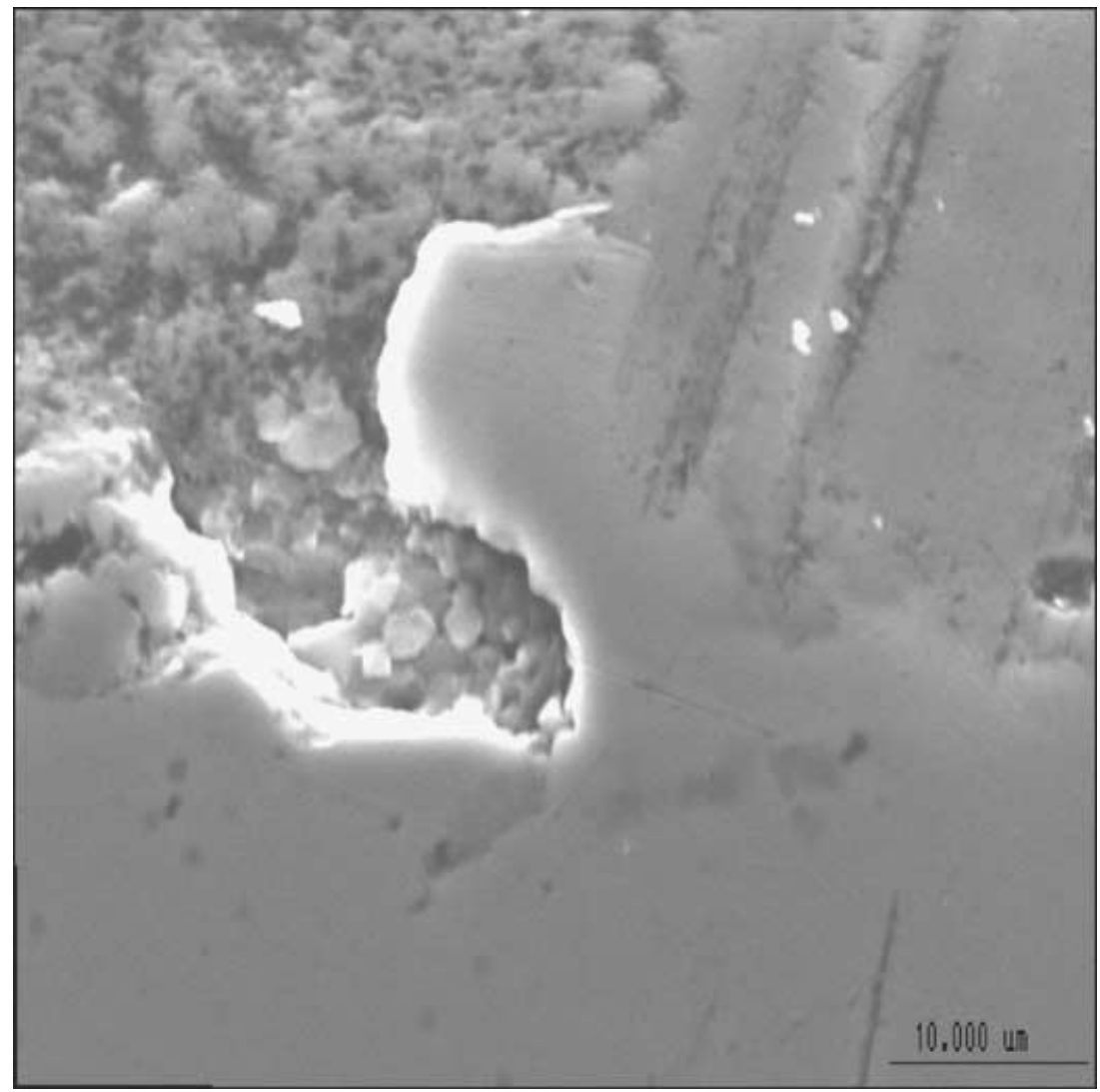

Fig. 14. SEM picture showing a probable Helmholz instability in the mixing zone containing oxides and salts.

inclusion separation, production, size distribution, composition statistics, etc. Therefore, as a first step, the liquid slag phase and flux were added to the present model in addition to the refractory. This resulted in model predic- tions of small but significant slag concentration in steel close to the steel/slag interface, as shown in Fig. 11. The predictions even indicated some slag entrapment close to the ladle shroud, as seen in Fig. 10. These results then 


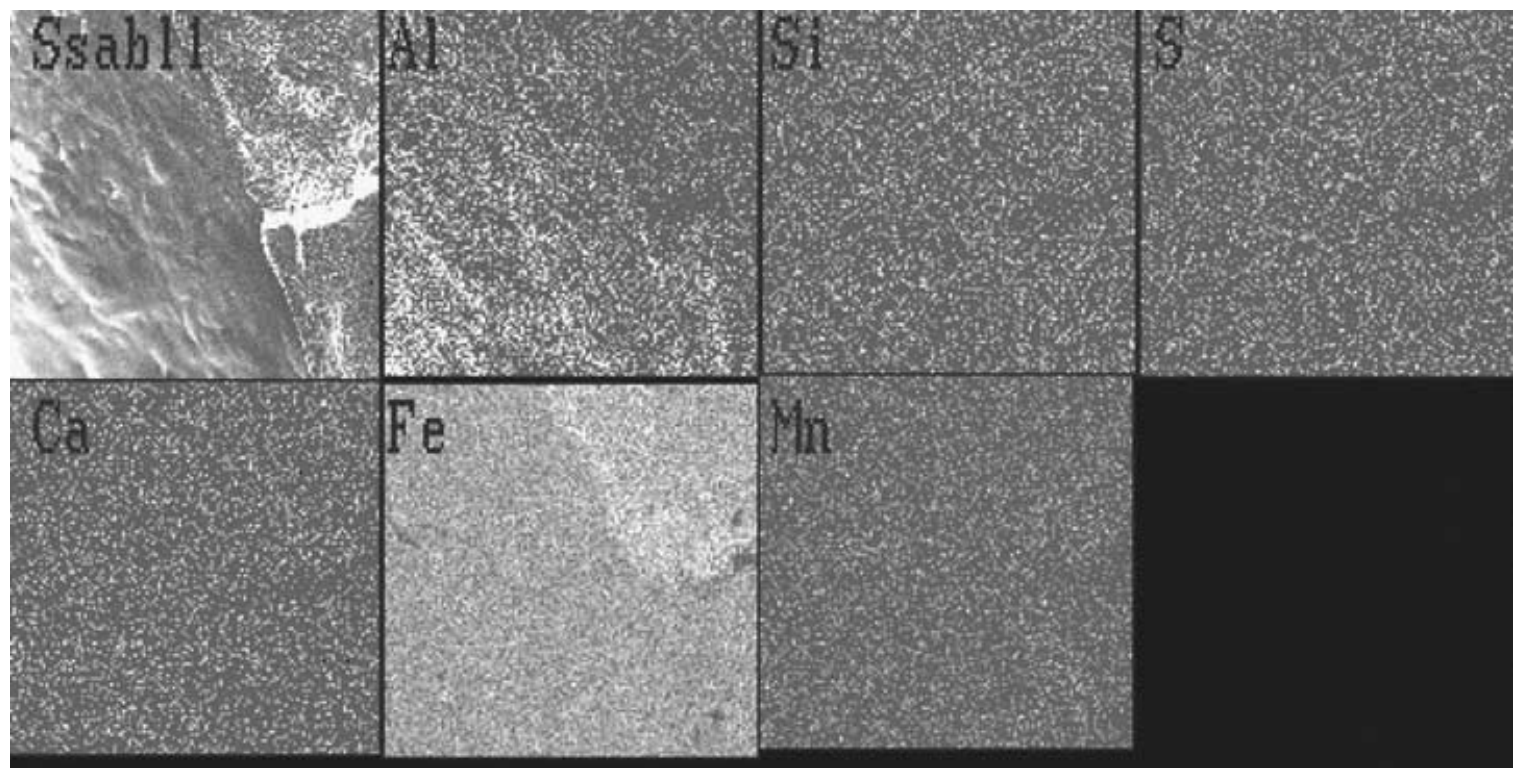

Fig. 15. X-ray mapp of mixing zone showing component contents in different slag layers, also indicating Fe-content above the Al-layer.

need to be verified. Therefore, a new sampling technique (MISS) was developed in order to sample the slag/metal interface in a vertical cross section through the interface. With this technique a sample with the shape of a rectangular plate showing a nearly instantaneous picture of the steel/slag interface could be obtained and studied by US, LOM, SEM and AFM techniques.

As noted, apparent similarities were found when comparing the result from the US study shown in Fig. 12 with the corresponding prediction of flow and concentration profiles shown in Fig. 10. This could be taken as evidence that the predicted slag concentrations were quite reliable. However, further and more detailed studies of the sample were necessary to confirm the conditions at the slag/metal interface. Fig. 13 shows an SEM picture of the slag/metal interface. The shape of the interface in the figure is very complicated but yet shows a pattern that is very much the same as could be expected from the 'The KelvinHelmholtz Instability' characterised by growth of waves, later rolling up into (small) vortices. This can assume to substantiate that the understanding of the physics upon which the model is based is principally correct. Fig. 14 shows a magnified picture of one of the vortices at the interface. In this picture the expected shape of the instability is readily recognised. Also seen in the figure are some particles that appear to be slag droplets torn off from the slag by the instability. Thus, referring to the question posed in the section named Predictions, it seems possible for slag penetration into steel to occur at these low, almost horizontal, velocities. To even further strengthen our understanding of the situation near the ladle shroud, SEM analyses at different positions as marked in Fig. 12 were made. The result of the analyses can be seen in Fig. 16 . The figure shows that the Al-Si content increases on increasing the position number, i.e. from 1 to 3 . These results also confirm that the predicted and measured concentrations show the same behaviour.

The complicated shape of the interface might on one hand be because of the irregularities in density, and on the other hand there might be other mechanisms promoting the formation of mixing. For example, Richardson \& Brimacombe [31] have shown that turbulence is established in the interfacial region as a direct result of certain reactions and the corresponding transfer, which occurs in addition to turbulence, induced by the fluid flow. This interfacial turbulence arises when the reactions taking place involve surface-active substances. An eddy at the interface may raise or lower the interfacial tension locally, thereby causing contraction or stretching of the micro-scale interface, thus setting up turbulence at the physical boundaries. This leads to phase mixing, which can occur without stirring or macroscopic velocities at the phase boundaries. This micro-scale phenomenon could also distort the expected pattern and it is not considered in the present model of a continuous-casting tundish.

The presented illustration of the conditions at the slag/metal interface has some important implications for understanding both inclusion separation/flotation and slag entrapment in the tundish. Inclusion separation to slag seems not to be a simple process represented by separation against a flat surface, but a complex process where the inclusions are trapped for some time at 

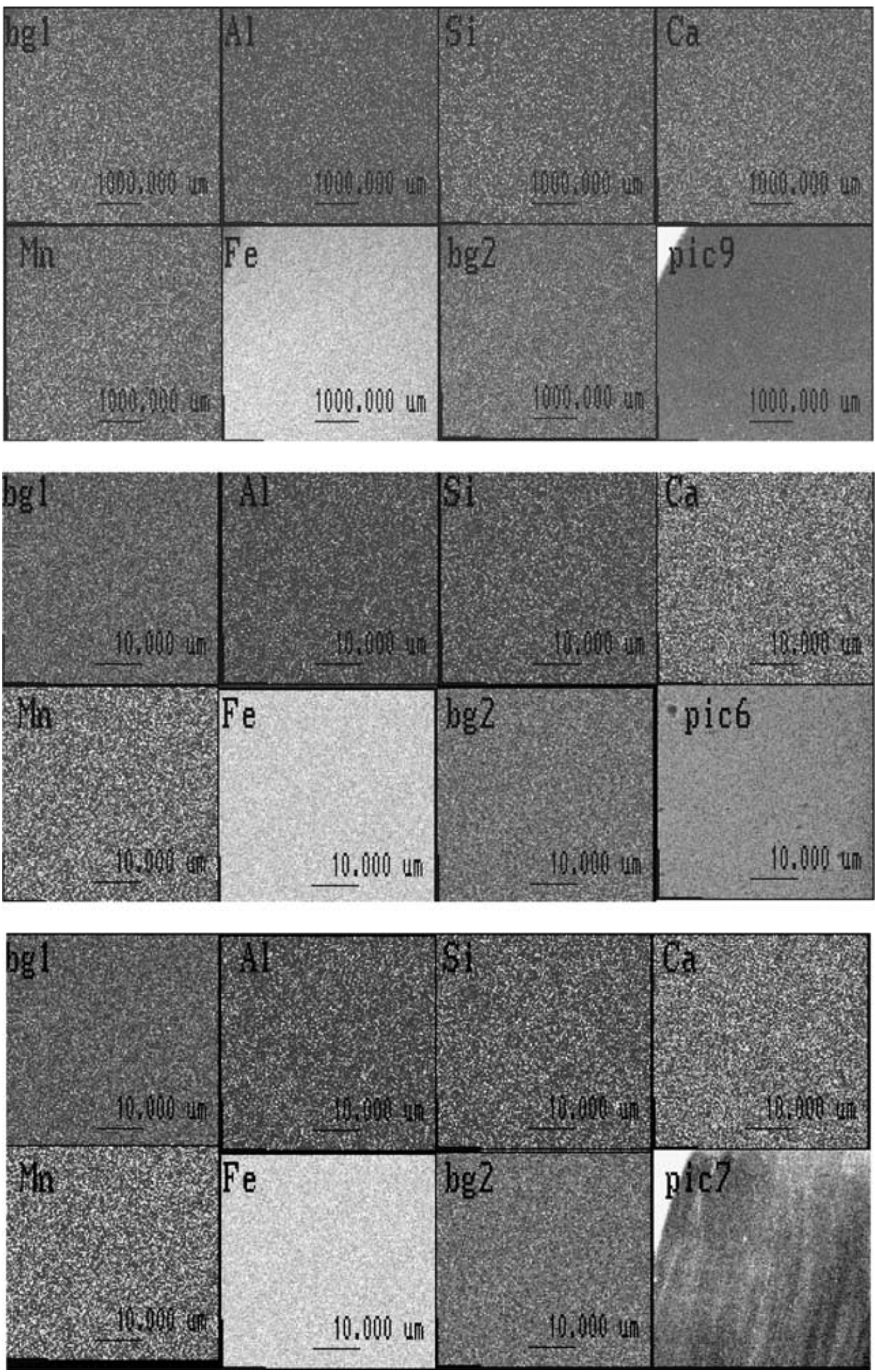

Fig. 16. X-ray mapp at the tree positions in Fig. 12 showing an encreasing Al-Si content towards point 3.

the interface itself by instability of the slag/metal interface and turbulence fluctuations. Slag particles might be engulfed by steel at the interface as a consequence of instability of the slag/metal interface and these particles could divide into numerous new inclusions, as illustrated in Fig. 8. The figure shows an entrapped and rising 30- $\mu \mathrm{m}$ inclusion, with a Cr-Ti core, that splits up into numerous small $\mathrm{Ca}-\mathrm{Al}$ and $\mathrm{Al}-\mathrm{O}$ inclusions 


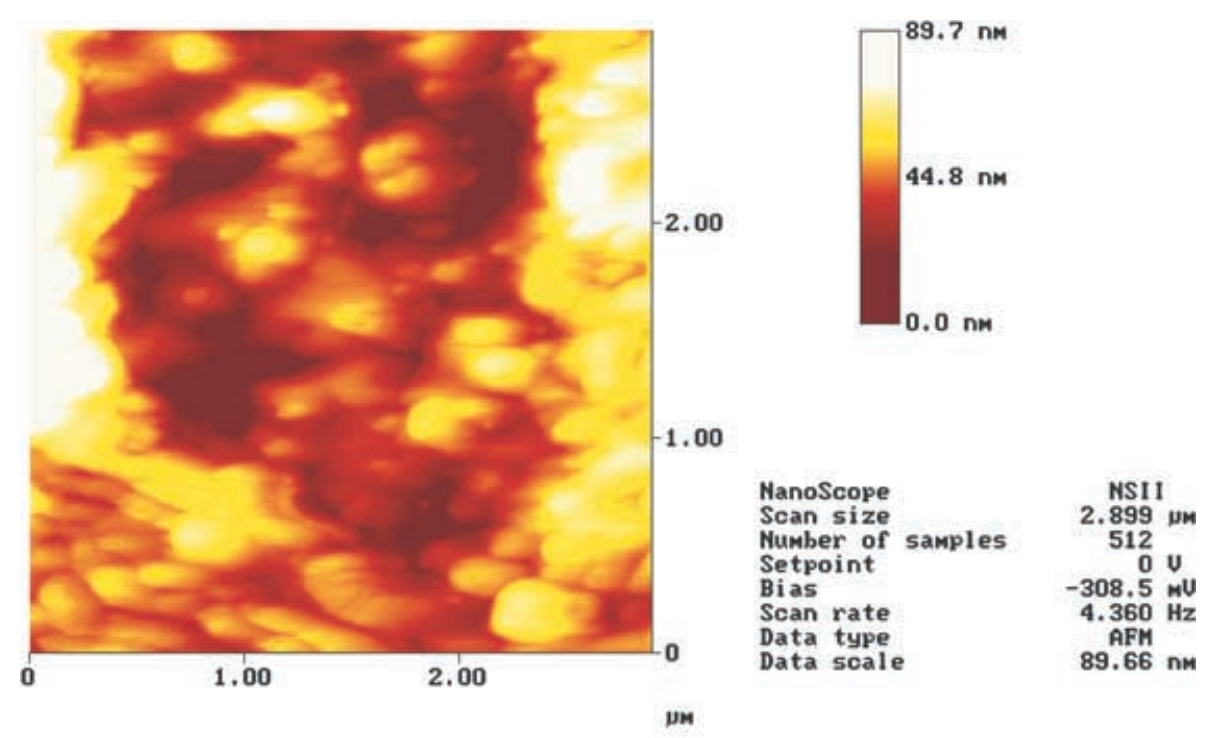

foums2.001

Fig. 17. AFM picture of $\mathrm{MnS}$ in perlite structure (bcc and $f c c$ ) showing well-developed bonds to the surrounding matrix.
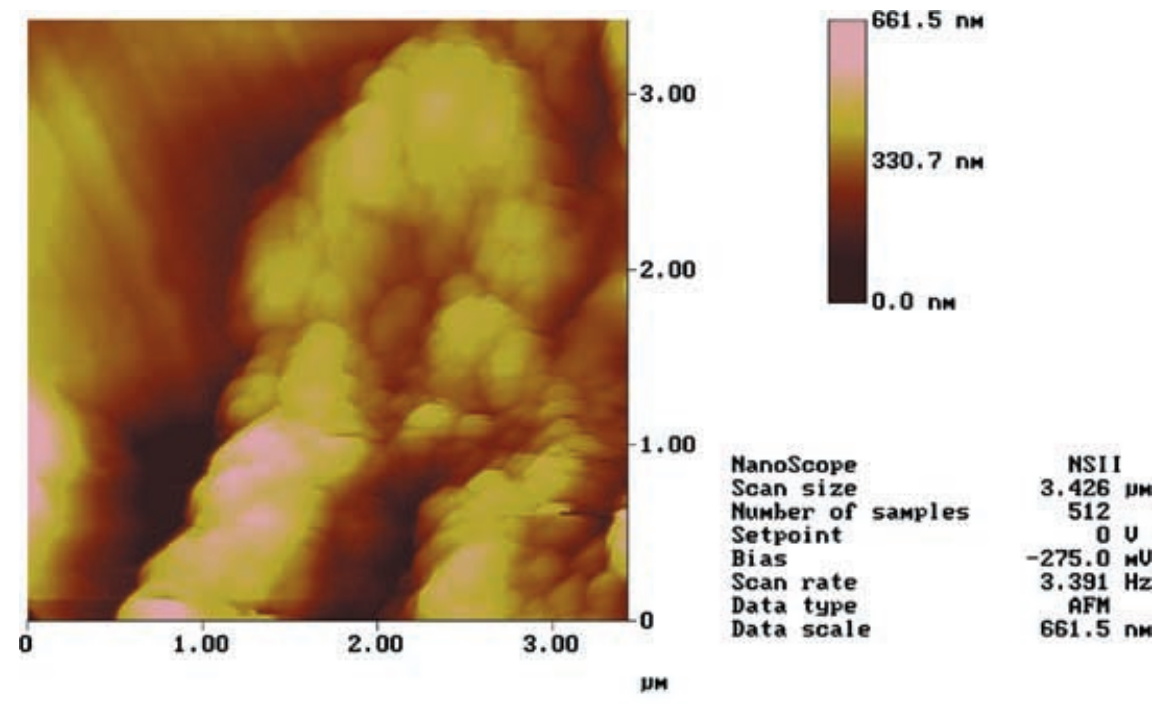

fp2inc12.005

Fig. 18. AFM picture of Al-oxide illustrating developed voids in a surrounding ferrite (bcc) matrix.

(a detailed picture of that inclusion can be seen in Fig. 9).

\section{Conclusion}

A model of a continuous-casting tundish, which, besides the steel phase, also considers refractory, slag and flux, has been developed and presented together with the basic ideas behind the development. The model was verified with velocity and temperature measurements in steel and refractory. The agreement between measured velocities and temperatures and the corresponding predictions was good.
In order to verify the fluid-flow modelling of the slag phase, a new sampling technique (MISS) was developed. This technique was used to sample the slag/metal interface in a vertical cross section, from the slag/metal interface and downwards to a depth of 10-12 cm. MISS samples studied in US, LOM, SEM and AFM verified the fluid-flow modelling of the slag phase and the understanding of the physics upon which the model is based.

With verified and reliable model predictions at hand, it has been shown that a comparative analysis of the effect of different configurations of flow guides in a specific tundish can be performed with respect to processes like inclusion floatation just by studying the 
predicted flow pattern for each configuration. Thus, it seems possible to improve inclusion flotation for each specific tundish by choosing a suitable configuration of flow guides determined from inspection of model predictions.

Further, some conclusions can be drawn regarding the conditions close to the slag/metal interface in a continuos casting tundish from the MISS samples and the combined use of US, LOM, SEM and AFM techniques. For example, inclusion separation to slag does not seem to be a simple process represented by separation against a flat surface, but a complex process where the inclusions are trapped for some time at the interface itself by instability of the slag/metal interface and turbulence fluctuations. Moreover, the slag particles might be engulfed by steel at the interface as a consequence of instability of the slag/metal interface and these particles could divide into numerous new inclusions, coalesce or become separated.

\section{Future work}

The next step in future development is to combine the fluid-flow calculation with relevant thermodynamic modelling, for example re-oxidation during the filling process. Also, modelling of growth and separation of inclusions should be incorporated into the model of a continuous-casting tundish.

Separate models of ladles, tundishes and moulds do not allow modelling of the connection between process parameters in some reactor and the final product quality. Therefore, a combined model of these reactors should be developed. This would make it possible to study the influence of any specific parameter on the final product.

To trace the influence of a change in a specific process parameter on the product quality, it is necessary to take samples (MISS or LSHR) in the different reactors and to perform detailed analysis (US, LOM, SEM and AFM) of the samples. In this way changes of process parameters could be coupled to product quality. This is an on-going project at MEFOS.

Illustrating the possibilities to study steel-inclusion interaction, 2 types of inclusions in a MISS sample were inspected by AFM technique, $1 \mathrm{MnS}$ inclusion (Fig. 17) and 1 alumina inclusion (Fig. 18). In the figures it can be seen that the MnS inclusion apparently has many bonds to its surrounding matrix (Fig. 17) while the alumina inclusion most probably has bonds only at lattice defects and furthermore seems to cause voids (Fig. 18).

\section{Acknowledgements}

Thanks to TO23-24, JK2343/97 and FB2340 for financial and technical support and to SSAB Tunnplåt AB, Luleå for the supply of samples and OVAKO Steel, Hofors for the supply and US-analysis of samples. Thanks are also given to the Department of Materials and Manufact. Eng. at Luleå University of Technology for supporting the analysis work. The authors would furthermore like to thank Professor Pär Jönsson at Department of Materials Sci. and Eng., KTH, Stockholm for fruitful discussions and for initiating the project while working at MEFOS. Finally, Dr Nils Almqvist at Department of Physics, Luleå University of Technology is acknowledged for his interest in and support of the AFM studies.

\section{References}

1. Mazumdar D, Guthrie RIL. ISIJ Int 1999: 39: 524.

2. Solhed H, Wahlberg B, Jönsson P. 5th International Conference on Clean Steel, Balatonfüred, Hungary. 1997: 2: $1-10$.

3. Prandtl L. Über Flüssigkeitsbewegung bei sehr kleiner Reibung, Verhandl. d. III Int. Mathematiker-Kongress, Heidelberg. 1904: Leipzig. 1905: 484-491.

4. Higbie R. Trans Am Inst Chem Eng 1935: 31: 365-389.

5. Danckwerts PV. Ind Eng Chem 1951: 43: 1460-1467.

6. Machlin ES. Trans Metall Soc AIME 1960: 218: 314-326.

7. Kraus Th. Schweiz Arch Angew Wiss Tech 1962: 28: 452460.

8. Asai S, Kawachi M, Muchi I. Scaninject III, MEFOS, Sweden 1983: 12: 1.

9. Mazumdar D, Nakajiima H, Guthrie RIL. Metal Trans B 1988: 19: 507.

10. Sahajwalla V, Brimacombe JK, Salcudean ME. Procedings of Steelmaking Conference, USA. 1989: 497.

11. Mietz J, Schneider S, Oeters F. Steel Res 1991: 62: 1.

12. Mietz J, Schneider S, Oeters F. Steel Res 1991: 62: 10.

13. Kim S-H, Fruehan RJ, Guthrie RIL. Iron Steelmaker 1993: 71.

14. Cramb AW, Jimbo I. Scaninject VII, MEFOS, Sweden 1995: 89.

15. Xiao Z, Peng Y, Liu C. Chin J Mater Sci Technical 1987: 3: 187.

16. Spalding DB, Villasenor F. PhysicoChemical Hydrodynamics 1987: 9(1/2): 379-386.

17. Wahlberg B, Solhed H. Internal MEFOS-report in Swedish, TM00013K, Mars, 2000.

18. Phoenics ver. 2. Encyclopaedia, CHAM Ltd., London (1994).

19. Kawai Y, Shiraishi Y. eds. Handbook of physico-chemical properties at high temperatures, The Iron and Steel institute of Japan, Japan 1988: 2.

20. Ye G. TDCALC, A thermodynamic calculation program for metallurgists and chemists, MEFOS report MF92047: 1992.

21. Allen BC. In Beer SZ, ed. Liquid metals-Chemistry and physics, Dekker, New York, 1972: 161.

22. Seetharaman S, Sichen Du, Zhang JY. JOM 1999: 51(8): 38-40.

23. Jonsson L, Jönsson P. ISIJ Int 1996: 36: 1127.

24. Jonsson L, Grip C-E, Johansson A, Jönsson P. Threephase (steel, slag, gas) modelling of the CAS-OB process, Proceedings of 80th Steelmaking Conference, Chicago, USA, April 1997.

25. Hallberg M, Jonsson L, Alexis J. Modeling of hydrogen and sulphur refining during vacuum degassing in a ladle furnace, SCANMET I, Luleå, June 7-8, 1999. 
26. Alexis J, Jönsson PG, Jonsson L. ISIJ Int 1999: 39: 772.

27. Christer Nilsson, SSAB Tunnplåt AB, Luleå, Sweden, Private Communication.

28. Solhed H, Leden B. Internal MEFOS-report in Swedish, BTF84027B, June 1984.

29. http://www.gmd.de/SCAI, search for Down-Port.

30. Olsson RG, et al. Trans Metallurgical Soc. AIME 1966: 236: 426-429.
31. Richardson FD. Metall Trans 1971: 2: 2747-2756

Address:

Henrik Solhed

MEFOS

Box 812, SE-971 25

Luleå

Sweden 